\title{
Licenciatura em pedagogia - séries iniciais do ensino fundamental na modalidade de educação a distância: a construção histórica possível na UFPR
}

\section{The distance education undergraduation course teaching licence in pedagogy - initial levels of primary education: a possible historical construction at Federal University of Parana, Brazil}

\author{
Ricardo Antunes de Sá*
}

\begin{abstract}
RESUMO
O presente artigo pretende evidenciar o processo de implantação do primeiro curso de graduação na modalidade de educação a distância da Universidade Federal do Paraná. Considerou os aspectos históricos, políticos e pedagógicos de seu processo de implantação, procurando retratar a concepção do projeto político pedagógico construído até o presente momento.
\end{abstract}

Palavras-chave: educação, educação a distância e pedagogia a distância.

* Mestre em Educação, Professor do Setor de Educação. Ex-Coordenador e Professor do Curso de Pedagogia - Séries Iniciais do Ensino Fundamental na modalidade de Educação a Distância (1999-2002). Membro fundador do NEAD (Núcleo de Educação a Distância) desde sua criação em 10/02/99. Doutorando do Programa de Pós-Graduação em Educação da Universidade Estadual de Campinas - SP. E-mail: ricadesa@uol.com.br 


\begin{abstract}
The present article intends to analise the first undergraduate course at the Federal University of Parana, Brazil. It has considered the historical, political, and pedagogic aspects of its implantation process, aiming at portraiting the conceptual framework within its pedagogical project developed up to the end of 2002.

Key-words: education, distance education, distance pedagogy.
\end{abstract}

Nós mesmos é que inventamos espantalhos para nós, com o nosso apego às honrarias, às riquezas, aos prazeres. Se buscarmos a verdade, o demônio fugirá. Ele a teme como à peste! Teresa de Ávila

\title{
Início de uma longa jornada
}

Em dezessete de julho do ano de dois mil no Centro Associado de Taquara (RS) aproximadamente a $90 \mathrm{~km}$ de Porto Alegre, na cidade do mesmo nome, iniciou-se o processo de implantação do Curso de Pedagogia - Séries Iniciais do Ensino Fundamental na modalidade de educação a distância. O curso segue um modelo de educação a distância semipresencial, sendo que sua carga horária prevê $30 \%$ de encontros presenciais e $70 \%$ de estudos a distância, assistida por acompanhamento pedagógico e orientação acadêmica. Este foi um projeto pioneiro no estado do Paraná, constituindo-se no primeiro curso de graduação a distância da UFPR.

O processo de institucionalização deste curso de graduação a distância iniciou-se após a deliberação pelo Conselho Universitário, em vinte e oito de janeiro de mil novecentos e noventa e nove, quando da institucionalização da Educação a Distância na UFPR, pela criação do Núcleo de Educação a Distância (NEAD) em 10/02/99, vinculado à Pró-Reitoria de Graduação. O NEAD foi criado com o objetivo de “....assegurar a concepção, produção, difusão, gestão, avaliação dos projetos e experiências inovadoras em educação a distância, congregando equipe multidisciplinar representativa das diversas áreas do conhecimento provenientes dos diversos Setores/Departamentos e Cursos da UFPR" (POLAK, 1999). 
O Núcleo da Educação a Distância passou a qualificar professores especialistas em educação a distância, bem como profissionais que atuariam no sistema de educação a distância como tutores e/ou orientadores acadêmicos.

"Com a institucionalização da educação a distância na UFPR, a Sociedade Civil através de entidades pública e privadas começam a demandar junto à universidade a oferta de cursos de graduação, sobretudo, cursos para formação de professores" (SA, 2001a, p. 25).

Esta demanda é fruto das novas diretrizes traçadas pela Lei 9.394/96 LDB, quando estabeleceu prazo para a qualificação em nível superior de todos os docentes que atuam na Educação Básica. Somente no Estado do Paraná, em torno de 30 mil professores que trabalham nas primeiras séries do Ensino Fundamental não têm formação em nível superior. A modalidade da educação a distância situa-se neste cenário como política de inclusão e de qualificação de profissionais da educação em pleno exercício.

Em setembro daquele mesmo ano (1999), o Conselho Setorial do Setor de Educação instituiu uma Comissão de Educação a Distância (Portaria n. ${ }^{\circ}$ 45/99-ED) com a premissa de elaborar uma proposta de Formação de Professores em nível de graduação na modalidade de educação a distância (EAD).

No ano seguinte, enquanto o Conselho de Ensino, Pesquisa e Extensão - CEPE em maio exarava a Resolução n. ${ }^{\circ}$ 54/00 que instituía o Currículo Pleno do Curso de Pedagogia - Séries Iniciais do Ensino Fundamental na modalidade de EAD, a Comissão de Educação do Setor de Educação trabalhava na construção do Projeto Político Pedagógico, em parceria com o NEAD no sentido de aprofundar, pesquisar e propor os encaminhamentos teórico-práticos para sua implantação em julho/2000.

No primeiro semestre de 2000, o Conselho Nacional de Educação credenciou a UFPR por três anos para oferecer o Curso de Pedagogia a distância (Parecer n. ${ }^{\circ}$ 358/2000-CNE) e o Ministério da Educação exarou Portaria n. ${ }^{\circ}$ 576/2000 autorizando o funcionamento do Curso.

A Universidade, então, por intermédio do NEAD, celebrou convênio com três entidades da sociedade civil a fim de viabilizar o processo de implantação da licenciatura, tendo em vista a carência de políticas e financiamentos públicos para a implantação e manutenção desta modalidade educativa, embora esteja previsto na Lei 9.394/96-LDB, na qual fica subentendida a necessidade de atendimento deste público pelas Universidades Públicas Federais, embora o MEC não tenha traçado políticas públicas para subsidiar a modalidade de EAD vista como política de inclusão.

As entidades selecionadas apresentaram características específicas para o atendimento de seu público e agregavam uma demanda muito grande de 
interessados em realizar estudos em nível superior, tanto no Estado do Paraná quanto em outros estados.

O primeiro convênio foi celebrado com a fundação LACTEC da região do Sudoeste do Estado do Paraná, tendo sua sede na cidade de Pato Branco, o que resultou na criação do Centro Associado de Pato Branco, com 200 vagas iniciais, congregando diversas prefeituras e instituições da região.

O segundo protocolo assinado estabeleceu parceria com a Fundação UNILLUZ da região Norte do Estado, na cidade de Apucarana, com 200 vagas. Criou-se o Centro Associado de Apucarana para atender instituições e prefeituras da região do Norte Velho.

O terceiro convênio celebrado resultou na criação dos Centros Associados de Taquara (RS) com demanda de 100 vagas e Maringá (PR), também com 100 vagas, junto à União Adventista Sul, entidade filantrópico-religiosa com uma rede de 500 escolas espalhadas pelo Brasil.

O Centro de Taquara atende alunos dos Estados de Rio Grande do Sul e Santa Catarina, enquanto que o de Maringá, os Estados do Paraná, São Paulo e Mato Grosso do Sul.

O quinto Centro Associado foi criado em 2001 com a celebração de convênio junto ao IABC (Instituto Adventista Brasil Central), entidade localizada no Estado de Goiás. A sede do Centro ficou localizada próxima à cidade de Anápolis, em Planalmira.

A iniciativa da Universidade por intermédio das parcerias interinstitucionais do Setor de Educação e PROGRAD/NEAD e os convênios que foram firmados com a comunidade externa, objetivou atender à demanda de qualificação de profissionais da educação que vêm atuando na Educação Básica, cumprindo papel político, profissional e social fundamentais na melhoria da qualidade da educação brasileira e na construção de uma democracia social.

Os professores/alunos que freqüentam o curso trabalham na rede pública e confessional de ensino e teriam imensas, senão total impossibilidade de freqüentar a escola clássica presencial semanalmente. São profissionais que atuam nas redes municipais (1. a $4 .^{\mathrm{a}}$ séries) de ensino, sendo noventa por cento de mulheres.A faixa salarial vai de trezentos a setecentos reais, a maioria está entre 18 e 55 anos e boa parte procura dedicar seu tempo para aperfeiçoar sua prática pedagógica em cursos e eventos.

Os objetivos do Curso de Pedagogia - Séries Iniciais do Ensino Fundamental na modalidade de Educação a Distância (EAD) são, dessa forma:

- Possibilitar um aprofundamento teórico/prático nas questões que envolvem o trabalho pedagógico escolar em sua totalidade e 
complexidade.

- Instrumentalizar os procedimentos teórico-metodológicos da pesquisa em educação, desenvolvendo conhecimentos científicos que lhes possibilitarão ver e intervir crítica e politicamente na realidade na qual trabalham.

- Possibilitar a compreensão das diversas concepções, metodologias e propostas de avaliação que fundamentam o trabalho docente nas diversas áreas do conhecimento, sobretudo, naquelas desenvolvidas de 1. a ${ }^{\mathrm{a}}$ 4. ${ }^{\mathrm{a}}$ séries do Ensino Fundamental.

- Propiciar a compreensão das características do papel do professor na Educação Básica brasileira e as relações e implicações do seu saber/fazer com o contexto social mais amplo.

Todos os alunos selecionados por meio de Teste Seletivo (2000 e 2001) estão vinculados às entidades parceiras da UFPR e são essas que custeiam as despesas aluno/mês, sendo totalmente gratuito para o aluno.

As entidades suportam financeiramente os custos do programa, repassando recursos para o custeio dos Centros Associados, incluindo aí o pagamento das horas/aula dos professores tutores, da compra de livros e reprodução de textos, do funcionamento da secretaria etc. Outra parte do repasse cobre o pagamento dos deslocamentos, das diárias e da alimentação dos docentes, bem como as horas-aula dos encontros presenciais, as horas de orientação acadêmica a distância do docente para o professor tutor e a correção das avaliações presenciais realizadas nos Centros Associados pelos alunos.

Os Centros Associados fazem parte do sistema de educação a distância, criado pelo Núcleo de Educação a Distância (NEAD), constituindo um tipo de campus avançado da Universidade para a oferta de Cursos na modalidade de EAD.

O Centro Associado é uma unidade do Núcleo de Educação a Distância (NEAD), cuja finalidade específica é: a) Desenvolver e apoiar as atividades didático-pedagógicas e de investigação referentes a EAD. b) Promover convivências e encontros com os tutores, incrementando o desenvolvimento sociocultural do seu respectivo contexto. c) Garantir o relacionamento aluno/tutor utilizando estratégias, procedimentos e tecnologias que permitem diagnosticar os problemas de aprendizagem e as principais necessidades dos alunos, a fim de prover as intervenções que se fizerem necessárias (MARTINS e KRELLING, 2000, p. 2). 
A estrutura administrativa do Centro Associado compreende um diretor administrativo, um diretor acadêmico, um secretário, uma bibliotecária e um representante da comunidade.

A direção administrativa é de responsabilidade da entidade conveniada e coordena e supervisiona as atividades do Centro Associado (CA), tais como a contratação dos professores-tutores, a aquisição das referências bibliográficas, a organização de instalações e acomodações para os encontros presenciais e, sobretudo, para o funcionamento da unidade nos momentos de tutoria presencial e a distância.

O diretor acadêmico, um professor da universidade, é designado pelo Reitor da UFPR, após consulta ao NEAD e dentre suas atribuições está a garantia de que as práticas das atividades acadêmicas e didático-pedagógicas sigam em consonância com o projeto pedagógico do curso e as políticas de EAD do Núcleo de Educação a Distância da Universidade. ${ }^{1}$

O papel do diretor acadêmico tem sido de fundamental importância no sistema de EAD da UFPR garantindo que o Centro Associado organize-se e desenvolva o atendimento administrativo e tutorial para os alunos nos momentos presenciais e a distância e, sobretudo, para que o padrão de qualidade do ensino ofertado pela Universidade esteja sendo observado pelos profissionais que atuam nas diversas funções já mencionadas.

A frequiência com que os diretores acadêmicos atendem aos Centros Associados dependerá do movimento dos cronogramas de Curso. No caso dos Centros Associados de Taquara, Maringá e Planalmira, tem se dado nos encontros presenciais de janeiro e julho, isto porque o curso é concentrado nesses Centros, conforme convênio. Já para os Centros de Apucarana e Pato Branco, o deslocamento às unidades, por parte do diretor acadêmico é maior, em torno de uma vez ao mês, tendo em vista que nesses o cronograma de curso desenvolve-se "homeopaticamente", ou seja, ao longo do ano letivo com encontros todos os meses no final de semana.

1 Atualmente (fevereiro/2003) ocupam a função de Diretor (a) Acadêmico (a) os (as) seguintes professores (as): prof. ${ }^{a}$ Fátima Said - Centro Associado de Taquara, prof. José Vicente Miranda - Centro Associado de Apucarana, prof. Carlos Ávila - Centro Associado de Maringá, prof. ${ }^{a}$ Sandra Monteiro - Centro Associado de Pato Branco e prof. ${ }^{a}$ Eliane Précoma o Centro Associado de Planalmira. 


\section{Princípios norteadores da formação do licenciado em Pedagogia na modalidade de EAD}

O referencial teórico-metodológico que norteia o Projeto Político Pedagógico do Curso de Pedagogia - Séries Iniciais do Ensino Fundamental na modalidade de educação a distância, toma o trabalho pedagógico escolar como princípio educativo e orientador de sua formação integral.

O princípio do trabalho evocado expressa uma dada concepção de educação que é entendida como um princípio central e determinante na construção do conhecimento, presente em todas as atividades humanas e que adquire configuração e especificidade em relação às condições de cada sociedade.

Ao tomar-se o trabalho como princípio educativo, compreende-se teórica e metodologicamente que é pelo trabalho que o homem se inscreve no processo histórico de construção de sua hominização.

Tomar o trabalho como princípio educativo na formação do professor é entender que esta categoria contribui para a compreensão da práxis educativa, sem descontextualizá-la, sem deixar de estabelecer as mediações entre o particular e o geral, entre a escola e a sociedade.

É no e pelo princípio do trabalho que o homem estabelece dialeticamente relações sociais e de produção com o conjunto dos homens, assim como, interfere e sofre interferências da sua relação com a natureza. É um princípio intrínseco à objetivação do homem neste mundo, que o princípio do trabalho indissociabiliza, do ponto de vista do conceito geral, e a concepção/execução, a teoria e a prática, embora quando tomado no âmbito das relações sociais capitalistas, mostre-se sob a ótica da fragmentação.

O trabalho pedagógico escolar, pois, torna-se o princípio educativo que caracteriza e incorpora todos os conhecimentos, competências e habilidades inscritas na atividade escolar, incluindo, especialmente, a atividade docente.

Para SA (1997, p. 75) "O espaço escolar apresenta suas especificidades, enquanto instituição que desenvolve um tipo de trabalho não material. A especificidade da escola é garantir o acesso, o domínio do conhecimento gerado pela humanidade, ao longo de sua história, bem como a permanência por parte das classes subalternas, propiciando-lhes a apreensão, a incorporação e a compreensão dos conteúdos escolares necessários ao exercício da cidadania e a emancipação moral e intelectual dos trabalhadores".

O profissional da educação (professor) deve conhecer e reconhecer o espaço escolar em sua totalidade, complexidade e diversidade. Seu trabalho torna-se um dos elementos importantes e constituintes do Projeto Político 
Pedagógico Escolar, determinado e determinante pelos novos paradigmas políticos, econômicos, culturais, tecnológicos, ideológicos e multiculturais.

A escola, hoje, é uma das instituições demandadas socialmente para responder às exigências de formação e (re)qualificação do cidadão contemporâneo, assim como qualificação e (re)qualificação docente em serviço para o nível superior. Formação esta que, além de atender a dispositivo legal, pretende garantir-lhes um aprofundamento e domínio dos fundamentos das ciências que estudam o fenômeno educativo.

A indissociabilidade entre a teoria e a prática reforça ainda mais a concepção teórica e metodológica do princípio do trabalho pedagógico escolar, porquanto demarca a observância constante no movimento dialético entre a concepção/execução, entre a reflexão e a ação como princípio norteador de todo o profissional da educação comprometido com uma atividade transformadora, emancipadora.

Outro princípio imbricado e que emana dos anteriores, porque são indissociáveis, é o princípio cognitivo e instrumentalizador do trabalho docente, a pesquisa.

Para FREIRE, pode-se dizer que o princípio da pesquisa “...Faz parte da natureza da prática docente a indagação, a busca, a pesquisa. $\mathrm{O}$ de que se precisa é que, em sua formação permanente, o professor se perceba e se assuma, porque professor, como pesquisador" (1997, p. 32).

A pesquisa é compreendida como prática indissociável da atividade de ensino, ou de ensinar, do professor. No contexto do Projeto Político Pedagógico torna-se um dos princípios norteadores que deve permear a concepção e elaboração do material didático, as atividades nos encontros presenciais e as orientações acadêmicas a distância, bem como a tutoria presencial e a distância.

Conforme alude DEMO: "pesquisa significa diálogo crítico e criativo com a realidade, culminando na elaboração própria e na capacidade de intervenção. Em tese, pesquisa é atitude do 'aprender a aprender', e, como tal, faz parte de todo processo educativo e emancipatório” (1993, p. 129).

A interdisciplinaridade insere-se neste curso como uma determinação frente à complexidade do fenômeno educativo contemporâneo que exige, das ciências da educação, uma nova perspectiva no enfoque, na reflexão e nas possibilidades de intervenção no trabalho docente.

Nos limites da organização do trabalho acadêmico, a incorporação do princípio da interdisciplinaridade vai materializar-se, sobretudo, nos Seminários Temáticos que encerram cada Núcleo Temático, investigando um tema comum, sob olhares específicos, mas com a perspectiva de se construir uma teorização interdisciplinar. 
A reflexão de FREITAS contribui para sustentar a compreensão que norteia o entendimento do princípio da interdisciplinaridade quando argumenta que:

Interdisciplinaridade é equivalente a integração, entendida como interpenetração de métodos e conteúdo entre disciplinas que se dispõem a trabalhar conjuntamente um determinado objeto de estudo.[...] tal integração ocorre durante a construção do conhecimento, de forma conjunta, desde o início da colocação do problema. O conhecimento é gerado em um nível qualitativo diferente daquele existente em cada disciplina auxiliar (1989, p. 106).

Esses princípios norteadores balizam as características e as especificidades (tempo, espaço, interação professor/aluno, professor/tutor, tutor/aluno etc.) que caracterizam a modalidade de educação a distância norteando o desenvolvimento do curso.

A partir dos princípios enunciados acima derivam os eixos metodológicos norteadores dos conteúdos curriculares:

Totalidade: insere-se neste eixo metodológico norteador a preocupação em garantir uma análise mais abrangente e significativa da escola, tanto em suas relações estruturais (socioeconômico e políticas) quanto em sua cotidianidade (organização, funcionamento, aprendizagem, ensino etc).

Historicidade: A abordagem que se pretende com este eixo metodológico norteador não é primordialmente trabalhar na perspectiva do que deve ser a prática pedagógica, mas do que é, possibilitando ao aluno/professor a compreensão do caráter construído das ciências e da escola.

Diversidade: Este eixo metodológico norteador assenta-se na perspectiva que para a construção do conhecimento é necessária a apreensão das relações que se impõem socialmente, entendendo que é a síntese das múltiplas determinações que garante a unidade da diversidade e, portanto, a especificidade humana. Entendendo que ensinar é confrontar-se com a diversidade, é preciso estar atento às transformações sociais, culturais, políticas e econômicas. 


\section{Matriz curricular}

A configuração disciplinar da Matriz Curricular do Curso reflete as características da organização do trabalho na academia, ou seja, a fragmentação do conhecimento em departamentos. Portanto, a matriz utilizada decorre, ainda, de uma concepção de ciência disciplinarizada, feudalizada, reflexos da Reforma de 68, mas que, mesmo após a Nova LDB (Lei n. ${ }^{\circ}$ 9.394/96), as Universidades e, sobretudo, as faculdades de Educação, não avançaram objetivamente em sua superação.

Na época da construção da proposta de licenciatura (1999), a Comissão de Educação esforçou-se para que a matriz curricular superasse a hegemonia departamental. No entanto, a rigidez institucional baseada em um modelo tradicional de ensino presencial exigiu uma matriz curricular com 29 disciplinas, o que não significou um avanço para uma proposta de curso na modalidade a distância.

Por outro lado, nos dois primeiros anos do processo de implantação do curso, esta mesma comunidade setorial, apesar de muita incompreensão ou indiferença de parte da comunidade discente e de boa parte da docente do Setor de Educação da UFPR, aprovou e viabilizou o processo de implantação do curso, contando com poucos visionários e "loucos" que têm atravessado e enfrentado o deserto, semelhante ao retratado por Boff.

O tempo do homem de Neandertal era tempo de transcendência; o australopiteco piticino, que era uma mulher, Luci, era uma mulher de transcendência. Ela deixou as florestas da África e começou a andar na savana árida, e como ali era muito seco, foi preciso desenvolver o cérebro para sobreviver. Assim, lentamente irromperam como seres humanos. Os demais irmãos que ficaram na floresta, cheios da abundância dos meios de vida e das frutas, continuam lá como primatas até hoje" (BOFF, 2000, p. 30-31).

Essas dificuldades decorreram em parte do desconhecimento da modalidade a distância, do desconhecimento dos benefícios gerados à comunidade e, principalmente, dos preconceitos políticos e ideológicos em relação à EAD e aos seus pioneiros. 
Criticar algo sem conhecê-lo e/ou reconhecê-lo e sem partir efetivamente para a compreensão do real e de suas contradições e, sobretudo, ter a coragem política para "dar a cara para bater" é continuar na floresta, na imobilidade, no conforto da crítica pela crítica.

Sem dúvida que a análise crítica das novas bases científico-tecnológicas e da expansão das relações capitalistas são posicionamentos pertinentes aos profissionais da Educação. Todavia, o desvelamento do real e suas contradições histórico-sociais, apenas, sem posturas de intervenção efetiva, de apropriação e articulação na e pela própria contradição, não tem, no meu entendimento, contribuído para nós outros, sairmos do discurso à práxis. Tem-nos imobilizado num arrazoado verborrágico que não avança e que precisa ser dialetizado, urgentemente, com vista a um processo de transformação, sob pena, como já vem acontecendo, "jogarmo-nos juntos com a criança e a água do banho” (SA, 2001a, p. 29).

Portanto, é salutar que se registre tal enfrentamento dentro da academia para que não se desconheçam as dificuldades políticas enfrentadas dentro da Faculdade de Educação, quando do processo de elaboração do Projeto Político Pedagógico e de sua implantação. Evidentemente que essa resistência à implantação de um programa de educação a distância tem a ver com a desconfiança dos educadores sobre a qualidade desta modalidade educativa que teve nos anos 70 características de "pacotes instrucionais" importados e concebidos à luz de uma pedagogia tecnicista e alicerçada numa vertente comportamentalista de aprendizagem (SA, 2001c).

Não obstante, esse enfrentamento revela, também, as relações de poder que existem dentro da Universidade, preocupadas muitas vezes com a manutenção de interesses privados na prática, mas que, no discurso, simulam uma racionalidade solidária, preocupada com o espaço público e com um compromisso social. ${ }^{2}$

Enfim, a Matriz Curricular estruturou-se em quatro Núcleos Temáticos, quais sejam: Núcleo Temático I - Concepção e Metodologia de Estudos em Educação a Distância; Núcleo Temático II - Fundamentos do Trabalho Pedagógico; Núcleo Temático III - Organização e Gestão do Trabalho Pedagógico; Núcleo Temático IV: Intervenção Pedagógica.

2 O autor aprofunda essas questões levantadas no parágrafo (SA, 2003). Discurso proferido na 8. ${ }^{a}$ Reunião do Colegiado de Curso no dia 31/01/03. 
O primeiro Núcleo Temático foi concebido com a preocupação de orientar os alunos sobre o curso e a modalidade de educação a distância, seus fundamentos, concepção, componentes, sistema de EAD etc.; oportunizando o conhecimento de toda a estrutura e funcionamento do Projeto Político Pedagógico, os objetivos, as formas e os processos de avaliação e acompanhamento acadêmico, bem como o papel do professor especialista, a concepção do material didático, o papel da tutoria.

As disciplinas "Concepção e Metodologia de Estudos em Educação a Distância I e II", dentro do mesmo Núcleo, foram concebidas no sentido de abordarem de forma sistemática e criteriosa o processo de estudo na EAD, suas características, formas de organização e importância para a permanência do aluno no processo pedagógico, além de possibilitar ao aluno a compreensão do funcionamento do Projeto Político Pedagógico do Curso.

O segundo Núcleo Temático caracteriza-se pelas disciplinas de fundamentos da educação, pela introdução à pesquisa em educação, à didática e à prática de ensino. A configuração deste Núcleo traduz a necessária instrumentalização do aluno quanto às ferramentas para análise e compreensão do fenômeno educativo.

Ao final, a disciplina Seminários Temáticos I conclui os trabalhos desenvolvidos com o exercício da prática interdisciplinar. São momentos presenciais quando se dão sínteses integradoras dos conteúdos tratados ao longo do respectivo Núcleo Temático a partir de temas geradores. Constituem-se em momentos interdisciplinares, na compreensão de que, os olhares de cada área do conhecimento estarão discutindo e contribuindo para o estudo, o entendimento teórico e metodológico e para a intervenção de um determinado objeto/fenômeno comum. ${ }^{3}$

O terceiro Núcleo Temático traz para a formação do licenciado uma compreensão da totalidade, complexidade e dinamicidade do processo pedagógico escolar e suas mediações com as políticas educacionais contempladas nas disciplinas: Organização do Trabalho Pedagógico da Escola, Políticas, Planejamento e Organização da Educação no Brasil e Processos Avaliativos. Também, insere-se neste Núcleo Temático III, a discussão sobre as novas linguagens da comunicação e suas mediações com a escola por meio da disciplina Mídia e Educação.

3 Neste momento (fevereiro de 2003), todas as turmas com entrada em 2000 já vivenciaram os estudos desenvolvidos pelos Seminários Temáticos I, os quais foram concebidos a partir do tema gerador: Escola e Família (MIRANDA, ROSÁRIO WU e PEREIRA, 2001). 
A questão da pesquisa em educação (instrumentalização teóricometodológica) se vincula às disciplinas de Metodologia da Pesquisa em Educação (Núcleo Temático II) e de Projetos em Educação I (Núcleo Temático III) e II (Núcleo Temático IV), assim como a Prática de Ensino II (Núcleo Temático III) articula-se com a Prática de Ensino I (Núcleo Temático II) e aquela com a prática III do Núcleo Temático IV.

O entendimento que se tem a respeito da Prática de Ensino atende aos reclamos da legislação quando compreende a Prática de Ensino de trezentas horas (300 horas) como elemento articulador entre formação teórica e prática pedagógica com vistas à reorganização do exercício docente em curso. A Prática de Ensino, além das atividades de observação e regência de classe deve incluir ações relativas ao planejamento, análise e avaliação do processo pedagógico, bem como envolver ainda as diversas dimensões da dinâmica escolar como: gestão, interação de professores, relacionamento escola/comunidade, relações com a família (Parecer n. ${ }^{\circ}$ 744/97. In: SA et al, 2001b, p. 55).

O Curso de Pedagogia - Séries Iniciais do Ensino Fundamental prevê 450 horas de Prática de Ensino, sendo desenvolvida na modalidade presencial por meio de atividades com o professor responsável em sala de aula, seminários sobre a realidade educacional e o ensino nas Séries Inicias. O professor terá 15 horas (10\%) presenciais das 150 horas previstas por Núcleo Temático (II, III e o IV) e as outras 135 horas a distância sob supervisão da tutoria.

No momento, a distância é considerado o trabalho desenvolvido pelo aluno, no seu próprio local de trabalho, ou seja, na efetiva prática pedagógica, a qual será supervisionada e orientada pelo tutor nos momentos de permanência dele no Centro Associado.

O aluno é, também, acompanhado e avaliado por meio de atividades como apresentações, relatórios, estudos de textos recomendados, exercícios de auto-avaliação, atividades, exercícios de pesquisa e leituras complementares.

Aqui, também se tem o encerramento dos trabalhos do Núcleo Temático III com os Seminários Temáticos II, com a mesma orientação teórica e metodológica desenvolvida no último Núcleo Temático.

O Núcleo Temático IV, denominado Intervenção Pedagógica, será implantado em 2003 e dará à formação do aluno um arcabouço teórico-prático das áreas do conhecimento, com enfoque para as primeiras séries do ensino fundamental, tratando da metodologia, conteúdo e avaliação do ensino de artes, língua portuguesa, matemática, educação física, geografia, história e ciências naturais. 
Núcleo temático I: concepção e metodologia de estudos em EAD
Disciplinas
C.H.
C.H.P. ${ }^{4}$
C Co/ Req./Pré

Concepção e Metodologia de

Estudos em

Educação a Distância I

$30 \quad 09$

02

Concepção e Metodologia de

Estudos em

Educação a Distância II

$30 \quad 09$

02

Núcleo temático II: fundamentos do trabalho pedagógico

$\begin{array}{llll}\text { Sociologia da Educação } & 120 & 36 & 08 \\ \text { Psicologia da Educação } & 120 & 36 & 08 \\ \text { História da Educação } & 120 & 36 & 08 \\ \text { Filosofia da Educação } & 120 & 36 & 08 \\ \text { Biologia Educacional } & 120 & 36 & 08 \\ \text { Antropologia } & 120 & 36 & 08 \\ \text { Didática } & 120 & 36 & 08 \\ \text { Metodologia de Pesquisa em } & & & \\ \text { Educação } & 120 & 36 & 08 \\ \text { Prática de Ensino I } & 150 & 15 & 10 \\ \text { Seminários Temáticos I } & 90 & 25 & 06\end{array}$

Núcleo temático III: organização e gestão do trabalho pedagógico
Disciplinas
C.H.
C.H.P.
C Co-Req./Pré

Políticas, Planejamento e Organização da Educação no Brasil $90 \quad 25 \quad 06$

Organização do Trabalho Pedagógico na Escola $\begin{array}{lll}120 & 36 & 08\end{array}$ 
Processos Avaliativos

$90 \quad 25 \quad 06$

Mídia e Educação

$90 \quad 25 \quad 06$

Projetos em Educação I

$\begin{array}{lll}120 & 36 & 08\end{array}$

Prática de Ensino II

$150 \quad 15 \quad 10$

Seminários Temáticos II

$90 \quad 25 \quad 06$

Núcleo temático IV: intervenção pedagógica
Disciplinas
C.H.
C.H.P.
C Co-Req./Pré

Conteúdo, Metodologia e Avaliação do Ensino da

Língua Portuguesa

$\begin{array}{lll}120 & 36 & 08\end{array}$

Conteúdo, Metodologia e

Avaliação do Ensino da

Matemática

$\begin{array}{lll}120 & 36 & 08\end{array}$

Conteúdo, Metodologia e

Avaliação do Ensino das

Ciências Naturais

$120 \quad 36 \quad 08$

Conteúdo, Metodologia e

Avaliação do Ensino da

Geografia

$120 \quad 36 \quad 08$

Conteúdo, Metodologia e

Avaliação do Ensino da

História

$\begin{array}{lll}120 & 36 & 08\end{array}$

Conteúdo, Metodologia e

Avaliação do Ensino da

Educação Física

$\begin{array}{lll}120 & 36 & 08\end{array}$

Conteúdo, Metodologia e

Avaliação do Ensino de

Artes

$\begin{array}{lll}120 & 36 & 08\end{array}$

Projetos em Educação II

$120 \quad 36 \quad 08$

Prática de Ensino III

$150 \quad 15 \quad 10$

Seminários Temáticos III

$\begin{array}{lll}120 & 36 & 08\end{array}$




\section{Coordenação e colegiado de curso}

O processo de gestão pedagógico-administrativo do Curso de Pedagogia - Séries Iniciais do Ensino Fundamental tem se mantido a partir de uma concepção teórica e prática que privilegia a ação coletiva coordenada e a observância do processo de comunicação bidirecional entre e por todos os elementos constituintes do sistema de EAD (UFPR/NEAD/SETOR DE EDUCAÇÃO/CCP/ata $4 .^{a}$ reunião, 2001).

Como meios de comunicação para organizar, planejar e articular o Projeto Político Pedagógico, envolvendo os cinco Centros Associados e as nove turmas, todos espalhados a centenas de quilômetros da UFPR, conta-se com a utilização da internet, do sistema telefônico e do correio. A internet é a ferramenta (meio) pela qual são veiculados os documentos (circulares, editais, avaliações, comunicados, planilhas de notas e informes, bem como o trabalho de orientação acadêmica a distância do docente para o professor-tutor que ocorre por meio da utilização da sala virtual (chat).

As reuniões de Colegiado de Curso são realizadas na sede (UFPR) de dois em dois meses com a presença de todos os representantes dos docentes das áreas/disciplinas, dos representantes dos professores tutores e dos alunos de cada Centro Associado.

As características dessas reuniões, diferentemente do que ocorre nos Cursos de graduação presencial, conta efetivamente com representação de todos os profissionais envolvidos na trama pedagógica. Antecedendo sempre essa grande plenária, a Coordenação de Curso articula ordinariamente, reuniões de trabalho com as áreas/disciplinas para garantir o aperfeiçoamento constante e a participação coletiva comprometida com a qualidade do ensino público na Educação a Distância.

Apesar da Resolução n. ${ }^{\circ} 18 / 00$-CEPE não avançar nessa concepção mais coletiva e representativa, o movimento do real é e será sempre determinante na transformação da norma, com vistas a reconceituação da teoria.

À medida que o curso se desenvolvia iam sendo criadas normatizações provisórias, procurando respeitar a legislação institucional, porquanto não se tinha e, ainda não se tem, normatização específica para a EAD. A Resolução n. ${ }^{\circ}$ 37-97-CEPE serve de referência, embora não tenha sido concebida para atender às especificidades de um programa de EAD, o que exige contínuo acompanhamento da legislação vigente, porém adaptando-a às demandas e peculiaridades de uma graduação a distância. 
Conforme o artigo $7 .^{\circ}$ do Capítulo III da Resolução n. ${ }^{\circ}$ 18/00 - CEPE, a gestão pedagógico-administrativa compete: a coordenação didática e a gestão dos cursos de graduação em EAD compreendem o colegiado e a coordenação de curso e sobre as competências do Coordenador de Curso, o artigo 13 diz:

a) coordenar a execução programática do curso, adotando as medidas necessárias para seu funcionamento; b) exercer a direção administrativa do curso; c) dar cumprimento às decisões do colegiado, dos órgão superiores da Universidade e do NEAD; d) convocar e presidir as reuniões do colegiado do curso; e) remeter ao NEAD o relatório semestral das atividades do curso de acordo com as instruções deste órgão; f) decidir matéria ad referendum do colegiado; g) discutir e propor junto a Comissão Central do Vestibular (CCCV) as normas, os programas oficiais dos conteúdos e a forma de elaboração do teste seletivo específico.

O trabalho do Colegiado de Curso, ao longo desses anos, possibilitou uma experiência viva de um processo democrático e representativo, na medida em que as reuniões se pautam por discussões pedagógicas com ampla representação de todos os segmentos partícipes do curso.

Durante a gestão 1999-2002, o Colegiado como órgão máximo do curso apreciava os trâmites implementados pela Coordenação e, à luz da legislação institucional e federal, estabelecia definitivamente os parâmetros norteadores e o aperfeiçoamento do Projeto Político Pedagógico, garantindo sempre a preocupação com a qualidade do ensino, bem como que o aluno da EAD tivesse seus direitos assegurados.

Foram produzidos entre 1999 e 2002, 15 fascículos dos materiais didáticos de diversas áreas/disciplinas que fazem parte do processo de aprendizagem do aluno da EAD. Além disso, foram publicados o Projeto Político Pedagógico (impresso e CD) e o Manual do Aluno da EAD - 2000 e 2001. Antes de os materiais didáticos chegarem às mãos do aluno, tinha que se encaminhar aos Centros Associados todas as referências bibliográficas das respectivas disciplinas para que os parceiros do programa providenciassem a aquisição das obras indicadas, as quais passariam a fazer parte das bibliotecas. Como todos sabemos, a instalação de bibliotecas nos centros de apoio constitui-se numa das exigências contidas nos Indicadores de Qualidade para Cursos de Graduação à Distância do MEC. 
Ao longo desses quase três anos foram elaborados 111 calendários de Orientação Acadêmica a Distância/Tutoria para cada disciplina ofertada por Centro Associado/Turma.

Durante esse período trabalhou-se para que a divisão de tecnologia do NEAD fosse construída a partir das discussões realizadas no Colegiado de Curso, um instrumento de registro virtual do processo de avaliação do aluno e do trabalho de orientação acadêmica realizada no NEAD pelos docentes. Essas fichas virtuais foram implantadas no $2 .^{\circ}$ semestre de 2002.

O Colegiado no ano passado instalou uma Comissão de Avaliação de Curso $^{5}$, da qual faziam parte, além da Coordenação de Curso, representantes dos professores e dos Centros Associados, iniciando seus trabalhos em julho/ 02, quando aplicou o primeiro instrumento de levantamento de dados nos Centros Associados.

\section{Organização do trabalho docente}

O trabalho docente na modalidade de educação a distância, embora tenha a mesma natureza, o mesmo objeto e os mesmos aportes epistemológicos que a educação presencial, assume características específicas e complexas.

Enquanto na presencial o docente estabelece relação "face-a-face" com o aluno, em tempo e espaços definidos, na educação a distância essa relação pedagógica configura-se a partir de elementos mediadores com tempos e espaços muitas vezes distintos.

O estudante na EAD não tem a presença constante e diária do docente, desta forma é preciso o desenvolvimento de um sistema pedagógico-administrativo que lhe garanta a possibilidade de interação com os docentes e professores tutores em todos os momentos (presenciais e/ou a distância), para que se sinta "cercado", como entendem os especialistas em educação a distância.

Esse sistema de apoio fundamenta-se, por um lado, na organização do trabalho docente, tutorial e na concepção e elaboração do material didático, e,

5 O Colegiado de Curso em sua 8. ${ }^{a}$ Reunião (31/01/03) alterou a composição anterior da Comissão de Avaliação do Curso. 
por outro lado, na administração, planejamento e organização dos Centros Associados e Coordenação de Curso (Colegiado).

Essa mediação caracteriza-se pela adoção de materiais impressos escritos e organizados pelos docentes, em linguagem dialógica e que incorporam os conteúdos a serem trabalhados pelos alunos tanto nos momentos de encontro presencial quanto nos momentos de estudos a distância.

Essa produção intelectual materializada numa linguagem impressa deve possibilitar que o estudante consiga percorrer o código escrito, compreendêlo e instigá-lo à pesquisa, a questionamentos, à reflexão.

No entanto, a linguagem não se prende, apenas, aos textos escritos ou impressos, mas incorpora como elementos de mediação na relação de aprendizagem as linguagens sonoras, da imagem, dos gráficos, dos signos etc. Esses recursos de linguagem estão presentes em um ambiente interativo de aprendizagem hospedado no site do NEAD destinado à mediação pedagógica que ocorre semanalmente no NEAD entre os tutores e os professores do curso.

Esta mediação destina-se a um trabalho de parceria dos professores e tutores no acompanhamento da disciplina e na orientação acadêmica dos alunos. Neste ambiente as ferramentas mais utilizadas são o chat e o e-mail. Na concepção inicial, o ambiente deveria contar com novas propostas para o uso pedagógico de suas ferramentas, uma vez que em seu período inicial de implantação uma grande atenção se voltou para a produção de todo o material impresso que precisava ser produzido para os semestres em andamento.

Do ponto de vista do tempo e espaço, essa relação se redefine na medida em que o espaço não é mais necessariamente a sala de aula em dias e horários definidos e rígidos, assim como o espaço para aprendizagem não terá um lugar fixo, necessariamente.

O mesmo pode-se pensar a respeito do tempo que compreende um movimento muito particular e flexível. Há uma flexibilidade maior no que tange aos momentos de estudo, não existindo mais uma determinação fabril de entrada e saída para se estudar.

Isto não significa que na educação a distância a flexibilidade espaçotemporal seja absoluta, anárquica e/ou aleatória; muito pelo contrário, haverá sempre uma relação de flexibilidade que atenda a um processo qualitativo de ensino-aprendizagem. Em programas educativos, socialmente comprometidos com um projeto político pedagógico norteador, portanto, o trabalho docente e todos os outros elementos componentes do sistema de EAD, apresentam uma dinâmica e uma flexibilidade mediadas à luz de um referencial político-filosófico. 
No curso em questão, o docente de cada área/disciplina pertence ao quadro de professores efetivos e substitutos do Setor de Educação, sendo responsável pela preparação e elaboração do material didático (fascículos) com as respectivas seleções de obras e a produção de textos introdutórios às seleções realizadas.Neste trabalho "não material" (SAVIANI, 1991, p. 20) o professor a cada unidade didática prevê uma série de atividades/tarefas a serem realizadas a partir das orientações inscritas no Projeto Político Pedagógico do curso (2001b).

Além da produção intelectual escrita, o docente responsabiliza-se em ministrar os encontros presenciais os quais representam uma carga horária de $30 \%$ da carga horária total de sua área/disciplina no Centro Associado, mediante calendário pré-estabelecido.

Nesses momentos presenciais desenvolve-se um trabalho qualificado de orientação acadêmica a respeito dos conteúdos tratados nas unidades didáticas do fascículo, bem como aprofundam-se aspectos e explicações mais detalhadas sobre as atividades que seriam realizadas pelo aluno, nos chamadas momentos de estudos a distância.

Como forma de garantir a orientação ao professor tutor nos momentos de estudos a distância do aluno, o docente assume o que se denomina de "Orientação Acadêmica a Distância do Docente para o Professor Tutor", cujo trabalho era acompanhar, orientar a distância o professor tutor, tendo como sede o NEAD, em dias e horários pré-definidos, mediado pelos recursos: telefone, fax ou internert (correio eletrônico e sala de bate-papo - chat) (UFPR/ NEAD/Setor de Educação/Coordenação/Circular). Esta atividade docente representa $50 \%$ da carga horária total da disciplina.

Com respeito às avaliações presenciais, as mesmas existem em todas as áreas/disciplinas realizadas pelos estudantes por escrito e sem consulta, excetuando as práticas de ensino e os seminários temáticos que têm processos avaliativos característicos e específicos, os quais são elaborados e corrigidos pelos docentes.

A prática docente na Educação a Distância passa a adotar uma espécie de divisão no trabalho de ensinar o aluno, porquanto o professor tutor tornase elemento co-participe do processo educativo, pois com ele que o docente terá que "dividir" sua, digamos, hegemonia na condução, organização e desenvolvimento das atividades docentes. Tornam-se "parceiros", "cúmplices", da mesma trama e do mesmo drama.

O acompanhamento permanente do trabalho tutorial, a qualificação científico-acadêmica permanente com reflexos na qualidade do trabalho desenvolvido junto ao aluno, são novas e específicas atribuições do professor da EAD. 
Para fazer frente a esta nova situação, o professor terá necessidade muito acentuada de atualização constante, tanto em sua disciplina específica, quanto em relação às metodologias de ensino e novas tecnologias. A redefinição do papel do professor é crucial para o sucesso dos processos educacionais presenciais ou a distância. Sua atuação tenderá a passar do monólogo sábio da sala de aula para o diálogo dinâmico dos laboratórios, salas de meios, e-mail, telefone e outros meios de interação mediatizada; do monopólio do saber à construção coletiva do conhecimento, através da pesquisa; do isolamento individual aos trabalhos em equipes interdisciplinares e complexas; da autoridade à parceria no processo de educação para a cidadania (BELLONI, 1999, p. 83).

Atribuições básicas do professor em EAD, conforme o Projeto Político Pedagógico (SA, 2001b, p. 49-50).

- Trabalhar na perspectiva da Concepção do Curso e de seu Projeto Político Pedagógico.

- Participar das reuniões pedagógicas do Colegiado de Curso.

- Elaboração do material didático, procurando aperfeiçoá-lo constantemente.

- Acompanhar sempre o trabalho da tutoria.

- Acompanhar e avaliar o processo de aprendizagem do aluno.

- Realizar atividades de extensão e pesquisa em EAD.

- Dispor de horário específico de permanência no NEAD, conforme consta no Projeto Político Pedagógico e no Regimento do Curso.

- Trabalhar nos encontros presenciais.

\section{Organização do trabalho de tutoria}

O professor-tutor é um profissional da educação que, após qualificar-se em Curso de Especialização para Formação de Professores em EAD ou de Aperfeiçoamento para Capacitação de Professores Tutores em EAD, ofertados pelo NEAD, submete-se a um processo de seleção por áreas/disciplinas para se habilitar à orientação tutorial do Curso nos Centros Associados.

Desenvolve trabalho alicerçado num tríplice aspecto: acadêmico, orientador e administrativo. 
Acadêmico porque trabalha em parceria com o professor docente e, estando em contato direto com os alunos no trabalho de orientação está em posição de fornecer para o professor docente valiosas compreensões do processo de aprendizagem dos alunos, da efetividade do material didático e da efetividade e adequação das abordagens pedagógicas empregadas.

O professor tutor é o ponto nevrálgico de todo o processo de mediação pedagógica, constituindo-se os sensores do curso e a caixa de ressonância para a contínua avaliação e adaptação dos vários aspectos do planejamento pedagógico. Esta concepção do papel do professor-tutor impedirá uma visão fragmentada do processo pedagógico que muitas vezes atribui ao tutor um valor secundário e de coadjuvante, um mero aplicador das atividades que lhe são designadas, o que imputa ao processo de educação a distância uma ruptura central na produção de conhecimento que, para ser contínua, se pauta no fluxo e refluxo de conhecimentos somente possível pela contribuição de todos os seus protagonistas.

Acadêmico também, porque acompanha e orienta o processo de aprendizagem do aluno, atendendo-o após os encontros presenciais ministrados pelo docente por meio de atividades previamente organizadas presencialmente e/ou a distância. Corrige e devolve para reexame as atividades/tarefas realizadas pelos estudantes, mediante critérios estabelecidos de comum acordo com o docente responsável.

Orientador na medida em que tem responsabilidade em acompanhar e motivar os alunos. Esse acompanhamento deve atender às particularidades dos alunos, pois muitos residem distante do Centro Associado ou não possuem nenhum colega de classe com quem possam dividir suas dificuldades e necessidades, e outros que desejam planejar com o tutor um estudo de grupo.

Vale ressaltar que o estudo em grupo tem se constituído um verdadeiro alicerce de sustentação para o processo de aprendizagem dos alunos, uma vez que ele reconstitui vários elementos da sala de aula presencial, tais como a freqüência dos encontros e o trabalho colaborativo entre pares. O tutor orienta os alunos na organização das tarefas que estão previstas em cada unidade didática para que o aluno aprenda a se organizar a distância e não se sinta impotente frente ao trabalho intelectual de estudar com método (GRAMSCI).

"...o bom tutor deveria promover a realização de atividades e apoiar sua resolução e, não apenas mostrar a resposta correta, oferecer novas fontes de informação e favorecer sua compreensão" (LITWIN, 2001, p. 99).

$\mathrm{O}$ atendimento presencial que ocorre no Centro Associado é organizado em pequenos grupos e/ou individualmente. Para atender o universo de 100 alunos/turma e poder acompanhá-los, corrigindo sua atividades/tarefas, o pro- 
fessor-tutor e o professor docente estabelecem um subcalendário em relação ao calendário oficial de cada área/disciplina/turma, a fim de que o aluno tenha noção do tempo para poder organizar suas leituras e a entrega de suas produções.

A perspectiva administrativa se coloca dentro do papel tutorial, demandando deste profissional o conhecimento do Projeto Político Pedagógico e a sua participação em todas as atividades realizadas pelo Centro Associado e Coordenação (Colegiado). Além de acompanhar o aluno orientando-lhe e garantindo-lhe condições de crescimento e apropriação e compreensão dos conteúdos implícitos nos materiais didáticos e nos encontros presenciais, o tutor deve incorporar tudo isto no quadro institucional.

Os procedimentos pedagógico-administrativos devem ser dinamizados pelo professor-tutor na outra ponta do sistema de EAD, pois sem esse engajamento inviabiliza-se tanto as tomadas de decisão em nível de gestão do curso quanto as diretrizes a serem concretizadas no processo pedagógico.

O NEAD desencadeou um processo de qualificação dos professores que iriam atuar na tutoria nos Centros Associados ao longo de 1999, 2000 e 2001. Durante o processo de implantação do curso foram realizados vários processos de seleção de professores tutores por área/disciplina, conforme critérios estabelecidos pela Comissão de Educação do Setor de Educação e, depois, pelo Colegiado de Curso, que levaram em conta as condições estabelecidas pelos convênios e as exigências do Projeto Político Pedagógico - PPP.

Os professores-tutores são contratados pelos Centros Associados e recebem por hora-aula trabalhada para cada turma/disciplina assumida de acordo com a área para qual foram selecionados.

Os professores tutores constituem hoje uma nova categoria profissional e têm pleiteado junto às autoridades constituídas da Universidade a criação de uma política institucional para viabilizar sua qualificação continuada. $\mathrm{Na}$ falta de um maior incentivo por parte do MEC e da própria UFPR, uma forma encontrada para que o professor-tutor possa se qualificar melhor para a área/ disciplina à qual trabalha tem sido sua participação nos encontros presenciais ministrados pelo docente, acompanhando o desenvolvimento do conteúdo, o enfoque teórico-metodológico privilegiado pelo professor e a linguagem etc.

Isto tem dado segurança ao professor tutor nos momentos seguintes ao processo de orientação, quando estará trabalhando com os alunos, o que tem possibilitado ao processo pedagógico uma condução mais unitária e consistente.

O Colegiado de Curso aprovou uma ficha como instrumento de acompanhamento e avaliação da aprendizagem do aluno, na qual o professor-tutor re- 
gistra o processo histórico de aprendizagem do aluno. Esses instrumentos estão disponibilizados on line e podem ser acessados mediante uma senha. Assim, o professor-tutor acessa o cadastro virtual dos seus alunos para poder efetuar o registro do processo de estudo de cada um. Tal instrumento contou com a contribuição da Subcoordenação Tecnológica do NEAD para sua efetiva utilização no sistema de gerenciamento de dados disponível na página do NEAD.

Estas novas atribuições Básicas da Tutoria em EAD, conforme o Projeto Político Pedagógico (UFPR/NEAD/CCP/CIRCULAR 002/2001) são:

- Conhecer os fundamentos, estruturas, possibilidades e metodologia em EAD.

- Informar os alunos sobre os objetivos, os conteúdos, os critérios da avaliação e outros aspectos significativos do Projeto Político Pedagógico do Curso.

- Estimular, motivar e orientar os alunos a desenvolverem suas atividades acadêmicas e de auto-aprendizagem.

- Dedicar-se a todos os alunos sob sua tutoria, considerando os ritmos e estilos de aprendizagem de cada um.

- Orientar a auto-aprendizagem, independência cognitiva e autocondução nos estudos.

- Assessorar os alunos no desenvolvimento de competências e habilidades teórico/ técnicas para o trabalho intelectual.

- Suscitar interesse pela investigação e uso de bibliotecas, mediatecas, laboratórios, instituições etc.

- Realizar sistematicamente exercícios de auto-avaliação, discussão de resultados de avaliações propostas nas Unidades Didáticas.

- Registrar sistematicamente e divulgar experiências do cotidiano pedagógico para os professores docentes, diretores acadêmicos, administrativos e coordenadores do curso e do NEAD.

\section{Concepção e produção do material didático}

O material didático construído para o curso foi concebido à luz dos objetivos, princípios norteadores e eixos metodológicos norteadores do Projeto Político Pedagógico. 
Isto implica na observância do Trabalho Pedagógico Escolar, como princípio educativo na orientação de nossas preocupações didáticopedagógicas (presencial e a distância) incorporando a Pesquisa e garantido a relação da Teoria e da Prática, bem como contemplar que os eixos norteadores metodológicos se manifestem nos conteúdos, nos textos e/ou nos materiais multimídia, ou seja, que a abordagem dada ao conteúdo privilegie, demonstre a historicidade, a totalidade e a diversidade do objeto/fenômeno estudado (SA et al, 2001b, p. 52).

O material é estruturado a partir de unidades didáticas que por meio das leituras básicas selecionadas levam o aluno à apreensão e compreensão do conhecimento científico concernente à área específica. Apresenta também textos introdutórios que orientam o estudante no processo de estudos e leituras.

Nesses textos introdutórios “....dever-se-á observar que o aluno não está presente naquele momento e, portanto, é fundamental que o docente explicite com clareza e objetividade a importância do(s) textos(s) selecionado(s) indicando a necessidade desta leitura para o contexto da disciplina e da sua formação [...] precisa garantir um diálogo entre o professor e seu aluno, para que estimule e motive a descoberta..." (SA et al., 2001b, p. 52-53). Estabeleceramse tarefas para cada unidade didática, a fim de que o cursista pudesse sistematizar suas leituras e estudos, apropriando-se do conhecimento científico, sobretudo nos momentos em que se encontra a distância. Para isso, conforme o Projeto Político Pedagógico, criaram-se quatro dimensões ou formas de exercício que possibilitam a aprendizagem.

"As atividades ao longo e ao final dos textos têm como intenção auxiliar o aluno na sistematização do material estudado, possibilitando-lhe questionamentos e reflexões a respeito do estudado e levando-o a relacionar a teoria com a prática. As atividades complementares irão complementá-las" (SA et al., 2001b, p. 53).

As leituras complementares indicadas representam a intenção de ampliação do quadro conceitual, viabilizando ao aluno um aprofundamento maior do tema estudado, abrindo a possibilidade para uma leitura de hipertexto, diversificando o conteúdo do texto central com a leitura de outros autores de concepções diferentes e/ou divergentes.

As atividades complementares de pesquisa e produção de texto são atividades que privilegiam a produção intelectual do aluno e sua capacidade de sistematização. Esta atividade sai do nível do pensamento e toma forma em textos produzidos a partir dos estudos realizados nos encontros presenciais, 
nos estudos a distância, bem como a partir de sua prática educativa cotidiana refletida. A pesquisa pode ser compreendida como um exercício constante, uma prática permanente à instrumentalização do estudante no sentido de aprender a "olhar" com rigor e com método os fenômenos sociais (educativo).

"Os Exercícios de Auto-Avaliação estão ao final de cada Unidade Didática e têm o papel de auxiliar o aluno na sua própria auto-avaliação. Ele pode perceber até onde caminhou com segurança e onde está encontrando dificuldades, bem como o que precisa compreender melhor" (SA et al., 2001b, p. 53).

Em cada disciplina e nas suas respectivas Unidades Didáticas, encontra-se uma série de atividades avaliativas propostas tais como: a) atividades e exercícios sobre $o(s)$ texto $(s)$ selecionado $(s) ; b)$ atividades complementares: pesquisa, produção de texto etc.; c) leituras complementares indicadas; d) exercícios de auto-avaliação da unidade didática. Essas atividades irão compondo um processo de acompanhamento e avaliação do processo de aprendizagem do aluno, culminando com uma avaliação ao final da disciplina que, de acordo com a legislação em vigor para a EAD, deverá se dar com a presença do aluno.

\section{Processos de avaliação da aprendizagem: construindo um percurso inovador}

O processo de avaliação da aprendizagem na educação a distância se sustenta em princípios análogos à educação presencial, porém demanda requisitos e considerações específicas como alude NEDER (1996):

“...um dos objetivos fundamentais da educação a distância deve ser o de obter dos alunos não a capacidade de reproduzir idéias, informações [...] o que deve importar realmente para um sistema de EAD é desenvolver a autonomia crítica do aluno, frente a situações que se lhes apresentam" (p. 82).

Os processos de avaliação da aprendizagem incorporam esses novos papéis que o professor-tutor, o docente e o aluno assumem, os quais se têm caracterizado como professor "coletivo" e estudante "autônomo".

Considera-se o aluno como sujeito ativo, reflexivo e atuante de sua própria aprendizagem. Ao realizar a avaliação do processo de apropriação do conhecimento sistematizado na EAD, o que importa é analisar a capacidade de 
reflexão crítica dos alunos, tendo em vista suas experiências na prática social e educativa e o modo como eles formulam novos conhecimentos, a partir dos referenciais teóricos trabalhados no curso.

"Por aprendizagem autônoma entende-se um processo de ensino e aprendizagem centrado no aprendente, cujas experiências são aproveitadas como recurso, e no qual o professor deve assumir-se como recurso do aprendente, considerado como um seu autônomo, gestor de seu processo aprendizagem..." (BELLONI, 1999, p. 40).

Os critérios de nota são idênticos aos vigentes na educação presencial (art.17, parágrafo $4 .^{\circ}$ da Resolução n. ${ }^{\circ} 18 / 00$-CEPE). Quanto à freqüência, o aluno deve ter $75 \%$ nos encontros presenciais previstos no projeto do curso (art.17, parágrafo $5^{\circ}$ ). O resultado da avaliação em cada atividade prevista na Unidade Didática e/ou na disciplina é expresso em notas, em escala de 0 (zero) a 10 (dez).

O aluno que não obtiver $75 \%$ de frequiência nos encontros presenciais previstos, nota acima de 7,0 (sete) nas atividades propostas na unidade didática e na nota do exame presencial escrito e sem consulta, permanece para uma segunda avaliação final, presencial, escrita e sem consulta.

$\mathrm{O}$ aluno deve percorrer todos os momentos avaliativos previstos nas unidades didáticas de cada área/disciplina, ou seja, ele só poderá avançar quando realizar todas as tarefas e/ou avaliações presenciais, mesmo que aritmeticamente tenha média.

As avaliações presenciais têm sido realizadas nos Centros Associados, sob o maior sigilo. Toda as provas eram enviadas por correio, pelos Diretores Acadêmicos ou pelos professores e com um ofício do professor autorizando que o professor-tutor as aplicasse. Era da responsabilidade do Centro Associado a preservação da seriedade do processo.

\section{Considerações de percurso}

No final de 2001 e início de 2002, a UniRede por meio do seu pólo de avaliação, designou comissão para avaliar os cursos superiores na modalidade a distância que pertenciam à UniRede. Participaram deste processo os cursos de graduação a distância da UFPR, UECE, UDESC e da UFMT. O roteiro do processo avaliativo estabelecia seis categorias: dimensão pedagógica, dimen- 
são material didático, dimensão orientação acadêmica, dimensão condições físicas e operacionais, dimensão de comunicação e dimensão referente ao impacto social.

Ao término do trabalho coordenado pela professora $\operatorname{Dr}^{\mathrm{a}}$ Kátia Siqueira de Freitas da UFBA, membro do núcleo de avaliação da UniRede, concluiu que o curso era recomendado sem ressalvas. FREITAS justificou dizendo: "a importância social do curso é inestimável; penso ser importante a sua expansão e contínua melhoria para atender o movimento de mudanças constantes da sociedade." Como aspectos positivos, lembrou "todo o clima de organização, entusiasmo, colaboração e entrosamento entre instituições - diretores técnicos - coordenadores - professores - tutores e alunos". Como aspectos negativos mencionou "o acúmulo de atividades das pessoas envolvidas que estão constantemente vencendo desafios". Por fim, conclui seu parecer salientando: "Recomendamos a continuidade do curso, sua expansão e contínuo aprimoramento dos materiais didáticos, dos recursos físicos e atualização permanente de pessoal em todas as instâncias, inclusive em elaboração de material para educação a distância. Recomendamos que, pelo menos $50 \%$ do quadro de pessoal, especialmente os docentes, sejam alocados no NEAD" (FREITAS, 2002, p. 9-10).

A Educação a Distância tem trazido inúmeras possibilidades educativas e enfrentamentos políticos e ideológicos. No tensionamento entre as possibilidades e os obstáculos, está a complexidade de uma trama pedagógica. Internamente há uma tensão, permeada pela racionalidade do modus vivendi do setor público, com um modelo de gestão burocrático, centralizador e corporativista.

Há grandes desafios internos à Universidade a serem superados. Para que a EAD possa desenvolver-se, respeitadas suas características e fundamentos, é preciso uma nova concepção organizativa, pedagógica e administrativa no espaço do trabalho público universitário.

Se para os próprios cursos ditos "presenciais" o modelo organizativo, acadêmico e administrativo está ultrapassado, mais ainda para a garantia de todo um sistema em rede como é o sistema de EAD.

Imbricado a isto, ressalta-se a luta por hegemonia instalada dentro da academia que tem valorizado os interesses de grupos que "privatizam" a instituição, que se arrogam "donos do público", "palmatória do mundo", em relação aos programas institucionais que são bens públicos e que não podem sofrer descontinuidade de percurso.

O conhecimento, o diálogo necessário entre as diferentes posições teóricas e metodológicas deve ser a verdadeira preocupação da academia. A 
luta partidária tem suas especificidades e um de seus objetivos é a conquista do poder político. Entende-se que nenhuma doutrina partidária deveria obliterar, interferir no diálogo epistemológico, na administração e na liberdade de pensamento, embora não se possa prescindir do diálogo político com os partidos.

Externamente existem obstáculos que inibem a participação e responsabilidade estatal na vida do cidadão devido aos determinantes macro-econômicos e sociais e, por outro lado, a necessidade de parceria com entidades civis que têm suas características, suas especificidades, regidas muitas vezes, pela imediaticidade do mercado e/ou pela lógica da relação custo/benefício. Daí resultando um financiamento proveniente de convênios que asseguram substantivamente a continuidade do curso, influenciando na forma de gestão pedagógica e administrativa e nos compromissos éticos e políticos assumidos pela instituição de ensino superior frente à comunidade de alunos dos centros associados.

O financiamento é um componente fundamental nos programas de EAD, porque em não havendo linhas públicas de financiamento, isto tem implicado no estabelecimento de relações com instituições da sociedade civil para garantir a criação, organização e manutenção de estudos em EAD.

Foram os convênios celebrados entre a universidade e um conjunto de instituições públicas (prefeituras) e privadas (entidades religiosas) que têm possibilitado o funcionamento do curso de graduação a distância, sem qualquer recurso do governo federal ou estadual.

A complexidade é termo adequado e método preciso para se poder entender e intervir numa dinâmica que envolve lógicas distintas, num mesmo Projeto Político Pedagógico, em que a dimensão política e a pedagógica devem se articular para garantir a qualidade do ensino na modalidade de educação a distância (SA, 2001d).

Na educação a distância o tempo e o espaço aparecem com movimentos distintos e, portanto, a comunicação bidirecional tem que ser o cerne do processo pedagógico cotidiano. “...Visceral é, também, a comunicação bidirecional entre todos os participantes desta modalidade educativa. Visceral, por mais incrível que pareça é a necessidade do trabalho em equipe, o que impõe-nos uma nova, novíssima postura como acadêmicos, como docentes, bem como aos nossos(as) professores(as) tutores(as) que constroem e promovem o processo educativo a distância" (SA, 2001, p. 10). 


\section{REFERÊNCIAS}

BELlONI, M. L. Educação a distância. Campinas: Autores Associados, 1999.

BORDENAVE, J. L. Pode a educação a distância ajudar a resolver os problemas educacionais no Brasil? Revista Tecnológica Educacional, Rio de Janeiro, v. 17, n. 80/ 81, p. 36, jan. /abr. 1998.

BRASIL. Lei n. 9394/96. Lei de Diretrizes e Bases da Educação Nacional. Diário Oficial da União, Brasília, seção 1, p. 1, 12 dez. 1996.

BRASIL, CONGRESSO NACIONAL. Decreto n. 2494/98. Regulamenta o Artigo 80 da Lei n. 9394/96. Diário Oficial da União, Brasília, 10 fev. 1998.

BRASIL, MINISTÉRIO DA EDUCAÇÃO E DO DESPORTO. Portaria n. 301/98. Diário Oficial da União, Brasília, 9 abr. 1998.

BRASIL, CONSELHO NACIONAL DE EDUCAÇÃO. Parecer n. 358/00 5 abr. 2000. Estabelece o credenciamento da Universidade Federal do Paraná para a oferta de cursos a distância na graduação e educação profissional. Diário Oficial da União, Brasília, 2000.

BRASIL, CONSELHO NACIONAL DE EDUCAÇÃO. Parecer n. 744/97 5 abr. de 2000. Estabelece o credenciamento da Universidade Federal do Paraná para a oferta de cursos a distância na graduação e educação profissional. Diário Oficial da União, Brasília, 2000.

BRASIL, MINISTÉRIO DA EDUCAÇÃO. Portaria n. 576 de 3 maio 2000. Credencia a Universidade Federal do Paraná a oferecer o Curso de Pedagogia a Distância, Licenciatura Plena com as habilitações Magistério dos Anos Iniciais do Ensino Fundamental e Magistério da Educação Infantil. Diário Oficial da União, Brasília.

BOFF, L. Tempo de transcendência - o ser humano como projeto infinito. Rio de Janeiro: Sextante, 2000. p. 30-31.

DEMO, P. Desafios modernos da Educação. Petrópolis: Vozes, 1993.

FREIRE, P. Pedagogia da Autonomia: saberes necessários à prática docente. São Paulo: Paz e Terra, 1997.

FREITAS, L. C. A questão da interdisciplinaridade: notas para a reformulação dos cursos de Pedagogia. Revista Educação e Sociedade, São Paulo, ano 10, n. 33, p. 105 $131,1989$.

LITWIN, E. O tutor na Educação a Distância. In: LITWIN, E. (Org.). Educação a Distância: temas para o debate de uma nova agenda educativa. Porto Alegre: Artmed, 2001. p. 93-110. 
MARTINS, O.; KRELLING, P. Manual de Orientação dos Centros Associados. Curitiba: Prograd/Nead, 2000.

MIRANDA, J. V. et al. Seminários temáticos I. Curitiba: Prograd/Nead/Setor de Educação, 2001.

NEDER, M. L. Avaliação na Educação a Distância - significações para definição de percursos. In: PRETI, O. (Org.). Educação a Distância - inícios e indícios de um percurso. Cuiabá: UFMT/Nead, 1996. p.75-90.

POLAK, Y. Iniciando o percurso em EAD na UFPR. In: POLAK, Y.; MARTINS, O. B.; SÁ, R. A. Educação a distância: um debate multidisciplinar. Curitiba: UFPR/ Prograd/Nead, 1999.

SA, R. A. A construção do pedagogo - superando a fragmentação do saber: uma proposta de formação. Curitiba , 1997. Dissertação (Mestrado) - Programa de PósGraduação em Educação, Universidade Federal do Paraná.

. et al. Projeto Político Pedagógico do Curso de Pedagogia - Séries Iniciais do Ensino Fundamental na Modalidade de Educação a Distância. Curitiba: Prograd/Nead/ Setor de Educação, 2001a.

Educação a distância: considerações preliminares de um percurso na UFPR. Tecnologia Educacional, Rio de Janeiro, v. 30, p. 152-153, jan./jun. 2001b.

. Fundamentos e políticas de educação a distância. In: MARTINS, O.; POLAK, Y. N. S. Educação a distância na Universidade Federal do Paraná - novos cenários e novos caminhos (Curso de Especialização para Formação de Professores em EAD). Curitiba: UFPR, 2001c. p. 1-53.

. Projeto político-pedagógico em EAD. In: MARTINS, O.; POLAK, Y. N. S. Educação a distância na Universidade Federal do Paraná - novos cenários e novos caminhos (Curso de Especialização para Formação de Professores em EAD). Curitiba: UFPR, 2001d. p. 421-431.

Discurso proferido no lançamento da publicação do Projeto Político Pedagógico do Curso de Pedagogia - Séries Iniciais do Ensino Fundamental na modalidade de EAD. Curitiba: 2001e. p. 13.

Discurso proferido na 8. ${ }^{a}$ Reunião do Colegiado Curso de Pedagogia-Séries Iniciais do Ensino Fundamental na modalidade de EAD. Curitiba: 2003. p. 22.

SAVIANI, D. Sobre a natureza e a especificidade da Educação. In: SAVIANI, D. Pedagogia Histórico-Crítica - primeiras aproximações. São Paulo: Cortez, 1991. p. 19-30.

UNIVERSIDADE FEDERAL DO PARANÁ - UFPR, REITORIA. Portaria n. 270/ 98. Comissão responsável por Elaborar Proposta de Educação a Distância na UFPR. Curitiba, 4 nov. 1998. 
UFPR, REITORIA. Portaria n. 370/99. Cria o Nead. Curitiba, 10 fev. 1999.

UFPR, SETOR DE EDUCAÇÃO. Portaria n. 45/99. Cria a Comissão de Educação a Distância do Setor de Educação. Curitiba, 4 nov. 1999.

UFPR, PRÓ-REITORIA DE GRADUAÇÃO. Portaria n. 08/99. Designa o Professor Ricardo Antunes de Sá para Coordenar o Processo de Implantação do Curso de Formação de Professores Para as Séries Iniciais do Ensino Fundamental. Curitiba, 12 nov. 1999.

UFPR, CONSELHO DE PLANEJAMENTO E ADMINISTRAÇÃO (COPLAD). Resolução n. 27/99 - Coplad, de 30 set. 1999. Estabelece o Regimento Interno do Núcleo de Educação a Distância (Nead) da Universidade Federal do Paraná. Curitiba, 30 set. 1999.

UFPR, CONSELHO DE ENSINO, PESQUISA E EXTENSÃO (CEPE). Resolução n. 54/00, de 7 abr. 2000. Estabelece o Currículo Pleno do Curso de Pedagogia - Séries Iniciais na modalidade de Educação a Distância do Setor de Educação - Prograd/ Nead/Setor de Educação. Curitiba, 7 abr. 2000.

UFPR, CONSELHO DE ENSINO, PESQUISA E EXTENSÃO (CEPE). Resolução n. 37/97, de 17 out. 1997. Estabelece Normas Básicas de Controle e Registro das Atividades Acadêmicas dos Cursos de Graduação. Curitiba, 17 out. 1997.

UFPR, CONSELHO DE ENSINO, PESQUISA E EXTENSÃO (CEPE). Resolução n. 18/00, de 14 abr. 2000. Aprova as normas básicas da atividade acadêmica dos Cursos de Graduação na modalidade de Educação a Distância da Universidade Federal do Paraná. Curitiba, 14 abr. 2000.

UFPR/NEAD/SETOR DE EDUCAÇÃO/CCP. Circular 002/01. Curitiba, 2001.

UFPR/NEAD/SETOR DE EDUCAÇÃO/CCP. Ata da 4. ${ }^{a}$ Reunião do Colegiado de Curso. Curitiba, 2001.

Texto recebido em 20 jan. 2003 Texto aprovado em 20 de mar. 2003 